\title{
DA DECODIFICAÇÃ̃ À PRODUÇÃO DE SENTIDO: O TRABALHO PEDAGÓGICO DO ENSINO DA LEITURA NA ROUPAGEM DA MULTIMODALIDADE DISCURSIVA E DOS MULTILETRAMENTOS
}

From decoding to the production of sense: the pedagogical work of the teaching of reading in the perspective of discursive multimodality and multiliteracies

De la decodificación a la producción de sentido: el trabajo educativo de la enseñanza de la lectura en la perspectiva de la multimodalidad discursiva y de los multiletramentos

\section{Silvio Profirio da Silva ${ }^{* 1}$}

${ }^{1}$ Mestrando pelo Programa de Pós-Graduação em Linguística e Ensino da Universidade Federal da Paraíba UFPB.

*Correspondência: Universidade Federal da Paraíba-Campus I - Conjunto Humanístico - Bloco IV Cidade Universitária - João Pessoa, PB - CEP 58059-900 e-mail: profirio.silvio@bol.com.br

\section{RESUMO}

Este trabalho tem como objetivo refletir sobre a relevância da efetivação de um trabalho didático do ensino da leitura ancorado na perspectiva da multimodalidade discursiva e dos multiletramentos. Decorrente disso, analisamos seis exemplares de gêneros multimodais (Charges, Memes e Tirinhas), objetivando identificar as marcas multimodais que contribuem, para a efetivação do processo de atribuição de sentido. Para realização deste trabalho, recorremos à revisão de literatura com foco nos referenciais da Linguística Aplicada, da Linguística de Texto, da Psicolinguística e da Pedagogia. Recorremos ainda à análise de gêneros multimodais procedentes do Grupo Humor Inteligente (Facebook). Os resultados demonstram que os gêneros discursivos analisados materializam distintos traços multimodais, tais como: cores, expressões faciais, formas, formatos, posições, texturas, tipografias etc. Esses traços aparecem entrelaçados à modalidade escrita da linguagem (letras, palavras e frases). Isso corrobora para a construção das informações materializadas por tais gêneros discursivos, bem como para o processo de atribuição de sentido por parte do leitor. A partir dos gêneros multimodais, o processo de produção de sentido é algo derivado não apenas do código alfabético da escrita. Nesse sentido, defendemos a necessidade de um processo educativo canalizado a formar leitores competentes e proficientes, que consigam processar os distintos exemplares de gêneros discursivas materializados nas rotinas cotidianas.

Palavras-chave: Leitura como produção de sentido. Multimodalidade discursiva. Multiletramentos.

\section{ABSTRACT}

This work aims to reflect on the relevance of the effectiveness of a didactic work of reading teaching anchored in the perspective of multimodality discursive and multiliteracies. As a result, we analyzed six exemplars of multimodal genres (Cartoon, Memes and Comic strips), aiming to identify the multimodal marks that contribute, to the effectiveness of the process of attribution of meaning. For accomplishment of this work, we resorted to literature revision with focus in the references of the Applied Linguistics, of the Text Linguistics, of the Psycholinguistics and of the Pedagogy. We also we resorted to analysis of multimodal genres from the Intelligent Humor Group (Facebook). The results demonstrate that the analyzed discursive genres materialize different multimodal traits, such as: colors, facial expressions, forms, formats, positions, textures, typographies etc. These traits appear intertwined with the written modality of language (letters, words and phrases). This corroborates for the construction of information materialized by such discursive genres, as well as for the process of attribution of meaning by the reader. From the multimodal genres, the process of producing meaning is something derived not only from the alphabetical code of writing. In this sense, we defend the need for an educational process aimed at 
training competent and proficient readers, that can process the different examples of discursive genres materialized in daily routines.

Keywords: Reading as meaning production. Discursive multimodality. Multiliteracies.

\section{RESUMEN}

Este trabajo tiene como objetivo reflexionar sobre la pertinencia de la realización de un trabajo didáctico de la enseñanza de la lectura anclado en la perspectiva de la multimodalidad discursiva y de los multiletramentos. Además, nosotros analizamos seis ejemplares de géneros multimodales (dibujos animados, memes y tiras), a fin de identificar las marcas multimodales que contribuyen a la realización del proceso de atribución de sentido. Para la realización de este trabajo, nosotros recurrimos a la revisión de literatura con foco en los referenciales de la Lingüística Aplicada, de la Lingüística de Texto, de la Psicolingüística y de la Pedagogía. También recurrimos al análisis de géneros multimodales procedentes del Grupo Humor Inteligente (Facebook). Los resultados demuestran que los géneros discursivos analizados materializan distintos rasgos multimodales, tales como: colores, expresiones faciales, formas, formatos, posiciones, texturas, tipografias etc. Estos rasgos aparecen entrelazados a la modalidad escrita del lenguaje (letras, palabras y frases). Esto corrobora para la construcción de las informaciones materializadas por tales géneros discursivos, así como para el proceso de asignación de sentido por parte del lector. A partir de los géneros multimodales, el proceso de producción de sentido es algo derivado no sólo del código alfabético de la escritura. En ese sentido, defendemos la necesidad de un proceso educativo canalizado a formar lectores competentes y muy competentes, que consigan procesar los distintos ejemplares de géneros discursivos materializados en las rutinas cotidianas.

Palabras clave: lectura como producción de sentido. Multimodalidad discursiva. Multiletramentos.

\section{INTRODUÇÃO}

No lastro da disseminação das tecnologias computacionais e informáticas, a internet tem fomentado a materialização de um amplo leque de textos derivados da concatenação de distintas modalidades da linguagem (escrita, oral e visual). Essa juntura de distintas semioses fomenta a potencialização da natureza multimodal. Os textos multimodais remetem não somente à escrita alfabética, mas também à imagem, às cores, às expressões faciais, aos formatos, aos gestos, às animações etc., como aponta Dionísio (2011). Essa guinada na noção de texto vem, continuamente, fomentando a potencialização de um amplo processo de moldagem no trabalho pedagógico do ensino da leitura.

Em um vasto contingente de décadas, o trabalho pedagógico do ensino da leitura concedeu primazia à decodificação silábica e frasal. Em vez de primar pela formação de leitores que conseguissem atribuir sentido diante das informações materializadas nas arquiteturas textuais, o trabalho pedagógico referente a essa habilidade linguística focou na decodificação do código alfabético e na decodificação de frases. $O$ que efetivou a materialização de práticas de reconhecimento e reescrita de sentenças linguísticas.

No dizer de Santos (2002a), desde meados dos anos 80, a roupagem tradicional de ensino da leitura calcada na decodificação de elementos alfabéticos e silábicos vem, continuamente, vivenciado um amplo leque de questionamentos. Tais questionamentos foram potencializados pelos postulados da Linguística e da Psicolinguística. Subjacentes a esses postulados, está a concepção de linguagem como forma de interação. A língua adquire o patamar de atividade social. A linguagem, por sua vez, obtém o posto de processo de interlocução, dissipando a condição de mero conteúdo escolar. Diante desse quadro, a aquisição da leitura tem como incumbência potencializar as competências discursivas e linguísticas dos sujeitos.

$\mathrm{Na}$ pauta dos debates traçados pela Linguística de Texto e pela Psicolinguística, a leitura 
obtém o posto de processo incontestavelmente marcado pela elaboração/construção de sentido. Para Kleiman (1989) e Koch \& Elias (2006), a efetivação da produção de sentido diante da materialidade discursiva dos textos é alavancada mediante a juntura de um amplo leque de saberes prévios do leitor. Soma-se a tais saberes, as práticas cognitivas projetadas pelos leitores, a saber, antecipações, inferências, paráfrases, seleções etc.

No bojo das orientações alavancadas pelos Parâmetros Curriculares Nacionais de Língua Portuguesa - PCNs (BRASIL, 1997; BRASIL, 1998), o ensino da leitura obtém como meta efetivar a formação de leitores autônomos, competentes e proficientes. Para realizar essa faceta, o trabalho pedagógico do ensino da leitura deve efetivar a promoção de situações didáticas marcadas incontestavelmente, pelos respaldos dos gêneros do discurso. É válido ressaltarmos que a efetivação de situações didáticas deve estar intrinsecamente atrelada à roupagem do letramento.

Para Luna \& Marcuschi (2015), o termo letramento remete à usabilidade das atividades de compreensão e produção de texto, estando tais práticas diretamente vinculadas às demandas cotidianas e sociais. A noção de letramento envolve, portanto, a multiplicidade de formas como os sujeitos fazem uso das habilidades de leitura e da escrita nos seus eventos cotidianos. Essa roupagem social do letramento transcende os elementos morfossintáticos, ortográficos e lexicais da língua. Ou seja, não é preciso apenas apropriar-se das convenções ortográficas e gramatiqueiras/linguageiras da escrita, mas, sim, aplica-las às demandas cotidianas.

$\mathrm{Na}$ esteira dos trabalhos alusivos à roupagem do letramento, emergem as discussões atinentes aos multiletramentos. Segundo Rojo (2012), os multiletramentos consistem na competência e na habilidade de lidar com o amplo contingente de formatos textuais e mídias audiovisuais. Ou seja, os multiletramentos e/ou letramento multissemiótico acontecem, quando os sujeitos conseguem lidar com as distintas convergências de linguagens e semioses propaladas nas rotinas do dia a dia.

Diante do exposto, este trabalho tem como objetivo refletir sobre a relevância da efetivação de um trabalho pedagógico do ensino da leitura ancorado na perspectiva da multimodalidade discursiva e dos multiletramentos. Decorrente disso, analisamos seis exemplares de gêneros multimodais (Charges, Memes e Tirinhas), objetivando identificar as marcas multimodais que contribuem, para a efetivação do processo de atribuição de sentido.

\section{TEXTOS MULTIMODAIS E MULTILETRAMENTOS: O TRABALHO PEDAGÓGICO DO ENSINO DA LEITURA SOB UMA NOVA ÓTICA}

De acordo com Silva \& Morais (2011), até os anos 80, o trabalho pedagógico do ensino de língua materna esteve calcado na transmissão mecânica de itens gramaticais, bem como na análise e no reconhecimento de formas linguísticas. Recorrendo a um viés dedutivo, o ensino de língua materna esteve calcado em uma lógica de funcionamento. $\mathrm{Ou}$ melhor, em uma sequência incontestável, a saber, abordagem de conceitualizações e definições, normas e regras gramaticais, exemplificações e, em seguida, atividades com foco na classificação da morfossintaxe. Assim, o trabalho pedagógico relativo a esse componente curricular tinha como cerne a metalinguagem.

Sob o lastro da roupagem tradicional de ensino, até meados dos anos 80, o trabalho pedagógico do ensino da leitura colocou em relevo a decodificação do código alfabético. De um lado, o ensino da leitura focava em elementos fonéticos e 
fonológicos, isto é, a oralização de textos efetivados mediante a modalidade escrita da linguagem. Por outro lado, o ensino dessa habilidade linguística primava pelo reconhecimento, bem como pela reescrita de sílabas e frases (SILVA, 2014a; SILVA, 2014b; SILVA, SOUZA \& CIPRIANO, 2015). Ou seja, a decodificação frasal e/ou informacional. Essa roupagem de ensino da leitura emergiu, em virtude das concepções de linguagem.

Na historicização do trabalho pedagógico do ensino de língua materna, assim como do ensino da leitura e da escrita, as rotinas educacionais presentes nas unidades escolas brasileiras estiveram assentadas nos subsídios da concepção de linguagem como expressão do pensamento, da concepção de linguagem como instrumento de comunicação e da concepção de linguagem interativa. De cada uma dessas concepções, emergiram elementos que fomentaram a potencialização de determinados tratamentos dados à leitura e à escrita.

De acordo com Fuza, Ohuschi \& Menegassi (2011), na concepção de linguagem como representação do pensamento, o texto obtém o posto de produto derivado da representação mental do autor. Diante dessa acepção, as atividades de leitura estavam assentadas na roupagem da extração de sentidos do texto e da expressão oral, alavancando, por conseguinte, a perspectiva de passividade do leitor. Este estava condicionado a simplesmente receber e reproduzir (mecanicamente) informações dispostas na materialidade textual. Ou seja, o leitor não detinha o papel de questionar, mas, sim, de reproduzir.

Sob o lastro da concepção de linguagem como representação do pensamento, a habilidade linguística da leitura estava focada em elementos fonéticos e fonológicos. Na visão de Barbosa \& Souza (2006), Santos (2002b) e Silva \& Luna (2013), as atividades de leitura primavam pela moldagem/conversão da modalidade escrita da linguagem para a modalidade oral. A abordagem do eixo leitura nas unidades de ensino brasileiras estava condicionada à oralização do código escrito, concedendo primazia à entonação, à pontuação, à pronunciação etc.

$\mathrm{Na}$ ótica de Fuza, Ohuschi \& Menegassi (2011), o cerne do trabalho didático do ensino da leitura estava na avaliação da expressão oral do alunado. Em outras palavras, o potencial dos alunos de expressarem-se corretamente, recorrendo, para tal, à oralidade. Diante desse quadro, os materiais didáticos da época focavam nos textos clássicos (isto é, textos da esfera literária). Com os gêneros da esfera literária, o alunado estava incumbido de realizar oralmente as frases desses textos, focando na expressividade e no ritmo. A partir dessas práticas, acontecia a avaliação da leitura em voz alta. A abordagem do eixo leitura, na acepção da concepção de linguagem como representação do pensamento, estimulava a mecanização da leitura com foco na oratória e na expressão oral. Esse viés de ensino persistiu até meados dos anos de 1960.

No dizer de Fuza, Ohuschi \& Menegassi (2011), na concepção de linguagem como instrumento de comunicação, a língua adquiriu o patamar de código que tinha por meta viabilizar a efetivação da transmissão de mensagens e informações. Diante dessa acepção, a leitura esteve canalizada na roupagem da decodificação de conteúdos textuais. As atividades de leitura estavam compelidas à mecanicidade da extração de informações, dissipando, assim, a reflexão face o texto.

Sob o lastro da concepção de linguagem como instrumento de comunicação, o trabalho pedagógico do ensino da leitura estava propenso a fomentar a potencialização do reconhecimento e da reescrita de informações deflagradas nas arquiteturas 
textuais. Para Albuquerque \& Coutinho (2006) e Barbosa \& Souza (2006), a abordagem do eixo leitura concedia primazia à decodificação da modalidade escrita da linguagem. Para realização dessa faceta, as atividades de leitura propalavam práticas de localização e de extração de informações materializadas no corpo textual.

Subjacente a essa roupagem de ensino da leitura como decodificação de elementos alfabéticos, estava uma noção de texto vinculada aos postulados estruturalistas da linguagem. Segundo Bezerra (2001), na ótica dos postulados estruturalistas e da teria da comunicação/informação, o texto é tido como uma construção constituída por inúmeras unidades estritamente linguísticas, a saber, letras, silabas, palavras e frases. Tais construções (isto é, os textos) são irrefutavelmente marcadas por mensagens e informações que deveriam ser decodificadas pelos leitores.

Para realização dessa faceta, as atividades de leitura requeriam do alunado o reconhecimento de informações e a reescrita na integra destas. A abordagem do eixo leitura nas unidades de ensino brasileiras estava - única e exclusivamente - calcada na decodificação frasal e informacional. Ou seja, as atividades didáticas de leitura requeriam dos alunos a localização de frases e informações específicas na arquitetura textual, estimulando-os a simplesmente reescrevê-las na integra. Essa roupagem de ensino da leitura persistiu até final dos anos de 1970.

De acordo com Fuza, Ohuschi \& Menegassi (2011), na concepção de linguagem como interação, a língua adquire uma roupagem social e discursiva. $\mathrm{Na}$ acepção da concepção interativa da linguagem, a materialização do discurso é potencializada, por intermédio dos textos. Estes, por sua vez, efetivam-se através dos gêneros do discurso. Nessa conjectura, os gêneros do discurso adquirem a alçada de Objetos de Ensino.
Essa roupagem social e discursiva da linguagem emerge nos anos de 1980. A concepção de linguagem como interação alavanca um processo de moldagem no trabalho pedagógico do ensino de língua materna. Na ótica de Bezerra (2010), os postulados linguísticos sociointeracionistas, as teorias do texto e do discurso, bem como os postulados atinentes ao letramento e as teorizações alusivas à aprendizagem fomentam a efetivação de um vasto contingente de modificações no ensino de língua materna.

Inúmeras são as teorias que, de formas variadas e em níveis diversificados influenciaram a metodologia de ensino de língua portuguesa. No entanto, nas duas últimas décadas do século XX e primeiros anos do século XXI, algumas têm-se destacado: a teoria sociointeracionista vygotskyana de aprendizagem, as de letramento e as de texto/discurso, que possibilitam considerar aspectos cognitivos, sociopolíticos, enunciativos e linguísticos envolvidos no processo de ensino/aprendizagem de uma língua (BEZERRA, 2010, p. 40).

No terreno das discussões sociointeracionistas e discursivas da linguagem, a leitura adquiriu o patamar de processo cognitivo indubitavelmente marcado pela atribuição de sentido, conforme pontuam Beaugrande \& Dressler (1981) e Koch \& Elias (2006). O cerne da leitura não está na decodificação dos elementos alfabéticos expressos na materialidade discursiva dos textos. O sentido, ou melhor, a atribuição de sentido obtém o posto de grande cerne da leitura.

Para Fuza, Ohuschi \& Menegassi (2011), na ótica da concepção de linguagem como interação, as atividades de leitura não estão mais compelidas à extração de frases e informações dos textos. O sentido não advém do discurso do enunciador nem da estrutura composicional dos textos. $\mathrm{Na}$ roupagem sociointeracionista de leitura, a atribuição/elaboração de sentido diante dos enunciados é potencializada 
mediante a interação entre autor e leitor, recorrendo aos subsídios (leia-se mediação) do texto. Tal momento é incontestavelmente marcado pela dialogicidade, configurando a leitura como uma atividade de coprodução de sentidos.

Entretanto, a atribuição de sentido não é algo efetivado, através da neutralidade. Pelo contrário, a elaboração de sentido diante do texto é materializada, por intermédio da concatenação entre um grande leque de saberes do leitor e as atividades cognitivas traçadas por este. Esse leque de saberes é composto pelos seus conhecimentos de expediente linguístico, textual e social (leia-se enciclopédico). Já o leque de atividades alusivas à cognição é composto, por estratégias cognitivas (marcadas pela espontaneidade) e metacognitivas (marcadas pela não espontaneidade), como evidenciam Kleiman (1989) e Koch \& Elias (2006).

Diante da incompletude das informações materializadas no texto, o leitor aciona seus saberes (de distintos expedientes) e sua cognição, aplicandoos aos enunciados materializados no corpo textual. Com isso, o leitor efetiva a junção entre o dito e o novo, corroborando para a construção de sentido (FUZA, OHUSCHI \& MENEGASSI, 2011).

Os Parâmetros Curriculares Nacionais de Língua Portuguesa - PCNs (BRASIL, 1997; BRASIL, 1998) alavancaram a efetivação de um substantivo processo de moldagem no trabalho pedagógico do ensino da leitura. Esse documento oficial desconstrói um tratamento histórico concedido ao ensino de língua. Referimo-nos, aqui, ao cerne dado à metalinguagem. Esse foco é dissipado, por esse documento oficial. Na esteira das discussões levantadas por esse documento, o trabalho pedagógico do ensino de língua materna é efetivado, a partir dos eixos didáticos de ensino (leitura, produção de texto, oralidade e análise linguística).
Com isso, o ensino da leitura recebe um equalizado diante dos outros eixos.

$\mathrm{Na}$ acepção dos Parâmetros Curriculares Nacionais - PCNs, a proficiência em leitura adquire o posto de grande cerne do trabalho pedagógico. O que está diretamente vinculado aos gêneros do discurso. O trabalho pedagógico do ensino da leitura deve, então, estar estribado na variedade textual. O que remete ao substantivo leque de gêneros do discurso materializados nos episódios e eventos cotidianos.

A efetivação da autonomia e da proficiência em leitura do alunado está diretamente vinculada a um trabalho marcado pelo envolvimento dos gêneros do discurso, bem como da abordagem das suas características constitutivas. São exemplos destas, a finalidade comunicativa, o plano temático (conteúdo temático), o plano composicional (composição ou forma composicional), o plano estilístico (estilo verbal ou estilo de dizer), o suporte discursivo etc. (SANTOS, MENDONÇA \& CAVALCANTE, 2007).

Em se tratando dos gêneros discursivos, os Parâmetros Curriculares Nacionais de Língua Portuguesa - PCNs (BRASIL, 1997; BRASIL, 1998) fomentam a potencialização de um trabalho pedagógico inquestionavelmente marcado não apenas pelos gêneros escritos, como também pelos gêneros multimodais. O intento disso é instigar a formação de leitores que consigam produzir sentido diante das múltiplas materialidades discursivas propaladas nas tramas cotidianas. Isso remete não apenas às arquiteturas textuais marcadas pela modalidade escrita da linguagem, mas também envolve as arquiteturas textuais marcadas pela multimodalidade discursiva. Aludimos, nesse ponto, aos documentos e/ou textos multimodais.

$\mathrm{Na}$ visão de Dionísio (2011), a multimodalidade discursiva é um processo marcado irrefutavelmente pela juntura de diferenciadas formas de representação. Fazem parte desse leque de formas 
de representação: a escrita alfabético-ortográfica, a imagem, a fala/oralidade, os gestos, as expressões faciais, as posturas corporais etc. A atuação de uma dessas formas de representação efetiva a potencialização de uma prática comunicativa monomodal. Entretanto, a juntura de mais de uma dessas formas de representação fomenta a potencialização de uma prática comunicativa multimodal.

Em se tratando dos textos, a multimodalidade discursiva fomenta a potencialização de um amplo leque de documentos calcados na juntura de elementos alfabéticos (letras, palavras e frases), elementos visuais, elementos sonoros etc. Dessa juntura entre elementos verbais escritos (escrita alfabética) e elementos audiovisuais, deriva o crivo multimodal. Na ótica de Bomfante (2011), a construção textual não é algo que repousa unicamente na modalidade escrita, falada ou visual da linguagem. $\mathrm{Na}$ roupagem da multimodalidade discursiva, a arquitetura textual passa a ser preenchida por um amplo leque de elementos semióticos. Estes remetem tanto ao plano verbal, quanto ao visual da linguagem.

Para elaborar uma mensagem, os recursos semióticos não estão restritos à escrita, à fala e à imagem, pois podem incluir tudo o que pode ser feito em diferentes formas, permitindo a articulação de diferentes significados sociais e culturais. Assim, paisagem semiótica passa a ser a denominação dada as diversas formas ou modos que ambientam o processo comunicacional. Os modos semióticos, tanto os verbais quanto os não verbais, são as diversas formas de representação utilizadas para compor um texto - questão trabalhada pela abordagem da Multimodalidade (BOMFANTE, 2011, p. 3).

No dizer de com Bomfante (2011), no lastro da Semiótica Social, as distintas formas de representação adquirem a nomenclatura de modos semióticos. Os postulados atinentes à multimodalidade discursiva vão, justamente, atuar no sentido de compreender a concatenação entre os diferenciados modos semióticos e seus subsídios na efetivação das práticas comunicativas. Em se tratando dos textos, os documentos multimodais envolvem a convergência de elementos das escrita alfabéticoortográfica, elementos visuais, cores, formas, formatos, tamanhos, sons etc. A composição textual é, então, derivada da convergência de um vasto leque de elementos semióticos.

As diversas formas de representação são denominadas modos semióticos para a Semiótica Social. A abordagem multimodal busca compreender a articulação dos diversos modos semióticos utilizados em contextos sociais concretos, ou seja, nas práticas sociais com o objetivo de se comunicar. Na Multimodalidade, a maioria dos textos envolve um complexo jogo entre textos escritos, cores, imagens, elementos gráficos e sonoros, enquadramento, perspectiva da imagem, espaços entre imagem e texto verbal, escolhas lexicais, com predominância de um ou de outro modo, de acordo com a finalidade da comunicação, sendo, portanto, recursos semióticos importantes na construção de diferentes discursos (BOMFANTE, 2011, p. 3).

Nos textos multimodais, a escrita alfabéticoortográfica não é o único modo de representação mobilizado na composição textual. Pelo contrário, o autor e/ou enunciador tem a possibilidade de fomentar a juntura de distintos modos semióticos. Não apenas distintos tipos de fontes, mas também tamanhos, formatos, cores etc. O simples emprego de uma cor no pano de fundo e, até mesmo, a ausência de uma cor são indicadores da intenção comunicativa do autor/enunciador. Ou seja, tudo isso consiste em elementos valiosíssimos que efetivam a materialização da intenção comunicativa desse sujeito. A escolha dos elementos semióticos que vão transitar na arquitetura textual está sempre vinculada aos propósitos comunicativos do autor/enunciador.

Segundo Bomfante (2011), a construção do discurso pode se potencializada de distintas e múltiplas formas, recorrendo, para tal, a diferenciados 
modos semióticos. Estes, por sua vez, são materializados nos textos. "Qualquer discurso pode ser construído de maneiras diferentes dependendo das combinações dos diferentes modos semióticos em forma de texto" (p. 4).

Diante dessa pluralidade semiótica na constituição dos gêneros discursivos propalados na pós-contemporaneidade, emergem as discussões atinentes aos multiletramentos. Para Rojo (2012), a definição de multiletramentos remete a dois prismas. De um lado, está a pluralidade de culturas propaladas na sociedade. Do outro lado, estão as multissemioses propaladas nas rotinas do dia a dia.

No primeiro prisma, está a multiculturalidade elou multiplicidade cultural. Em outras palavras, a variedade de culturas disseminadas na sociedade póscontemporânea. Esse viés multicultural preconiza a erradicação da discriminação face as variedades culturais. Em vez de focar nas produções culturais abastadas, cultas, dominantes e eruditas, o currículo escolar deve envolver também as produções culturais de massa. Esse viés dos multiletramentos é, portanto, refratário à discriminação das culturas minoritárias. Nessa acepção, os processos de ensino e aprendizagem devem conceder notoriedade a tais produções culturais, em vez de focarem apenas nas produções culturais canônicas e dominantes (ROJO, 2012).

Na visão de Rojo (2012), o segundo prisma, está a multiplicidade de linguagens elou semioses. Os textos propalados nas práticas corriqueiras são irrefutavelmente constituídos por diferenciadas semioses. Ou seja, a composição dos textos é derivada da juntura de distintas linguagens ou semioses. Essa junção de modos semióticos tem solicitado dos sujeitos habilidades e competências tangentes ao processamento textual. Tais habilidades e competências remetem aos multiletramentos.
É o que tem sido chamado de multimodalidade ou multissemiose dos textos contemporâneos, que exigem multiletramentos. Ou seja, textos compostos de muitas linguagens (ou modos, ou semioses) e que exigem capacidades e práticas de compreensão e produção de cada uma delas (multiletramentos) para fazer significar (ROJO, 2012, p. 19).

Os multiletramentos consistem, portanto, não ação de lidar com o grande leque de formatos textuais, bem como com a pluralidade semiótica disposta na sua materialidade discursiva. São exemplificações desse leque de formatos textuais: os gêneros multimodais, os gêneros digitais/hipertextuais, os arquivos sonoros e de vídeos etc. Esses materiais textuais trazem consigo um conglomerado de semioses, tais como: cores, diagramação, formas, formatos, imagens/ilustrações, efeitos de imagem, movimentos (animações) etc.

Emerge, assim, a necessidade da efetivação de um trabalho pedagógico do ensino da leitura canalizado na viabilização da promoção do letramento. Em outras palavras, um trabalho didático que não remeta apenas à roupagem da morfossintaxe, bem como à ortografia e ao léxico em torno das atividades de leitura. Mas, sim, um trabalho didático que esteja canalizado a efetivar a aplicabilidade e usabilidade das competências tocantes à leitura nos episódios cotidianos. Aqui, está a essência da roupagem do letramento ${ }^{1}$.

Diante dessa acepção, a propalação de linguagens e modos semióticos tem alavancado um amplo leque de transmutações nas atividades de

\footnotetext{
1 As discussões de Soares (2002) apontam a distinção entre alfabetização e letramento. No primeiro ponto, está a aquisição da escrita alfabética e dos seus elementos constituintes (letras, sílabas, palavras, frases etc.). A alfabetização está limitada ao código linguístico por si só. No segundo ponto, estão os usos e a aplicabilidade do código linguístico. Na roupagem do letramento, os componentes da escrita alfabética - letras, sílabas, palavras, frases etc. - não obtêm um fim em si mesmo. Pelo contrário, eles estão intrinsecamente atrelados à usuabilidade nas práticas cotidianas. Desse modo, a roupagem do letramento remete aos usos da escrita alfabética pelos sujeitos, que se envolvem em atividades de leitura e de escrita em suas práticas corriqueiras do dia a dia.
} 
leitura e de produção textual. Leitura e escrita, agora, são respaldadas sob o lastro da multimodalidade discursiva e dos multiletramentos. O que fomenta um vasto contingente de transmutações na efetivação dessa atividade. Isso tem requerido a efetivação de um processo de ensino e de aprendizagem calcado no viés dos multiletramentos e/ou letramentos multissemióticos, angariando a formação de discentes que consigam lidar com o grande leque de formatos textuais e as semioses dispostas nas suas materialidades linguísticas.

\section{MATERIAIS E MÉTODOS}

Em se tratando dos procedimentos metodológicos, de início, recorremos à revisão de literatura. Tal procedimento angariou o processo de apropriação, em torno de conceitos cruciais no tocante ao trabalho pedagógico do ensino de língua materna e da leitura. Com a revisão de literatura, apropriamo-nos da mais recente noção de leitura advinda dos postulados psicolinguísticos e das teorias do texto/discurso. Apropriamo-nos também da noção de multimodalidade discursiva e sua usabilidade na constituição dos gêneros discursivos, bem como no trabalho didático do ensino da leitura. Na revisão de literatura, recorremos, predominantemente, a referenciais da Linguística Aplicada, da Linguística de Texto, da Psicolinguística e da Pedagogia.

Após a revisão de literatura, iniciamos o procedimento de escolha dos textos multimodais a serem analisados. Para isso, recorremos à Página Humor Inteligente do Facebook. Como esse grupo publica diariamente distintos gêneros discursivos, que refletem a cerca de diferenciadas temáticas, adotamos os seguintes critérios de escolha: (a) gêneros multimodais; (b) gêneros que abordassem a temática política. A partir disso, escolhemos distintos gêneros publicados no segundo semestre do ano de 2016, mais especificamente, entre os meses de setembro, outubro, novembro e dezembro.

Para tanto, adotamos os seguintes critérios de análise: (a) finalidade comunicativa do gênero; (b) elementos multimodais presentes na construção composicional do gênero; (c) elementos linguísticos dispostos nos gêneros (recursos lexicais, semânticos e lexicais); (d) contributos dos elementos multimodais e semióticos, em prol da compreensão de texto.

\section{RESULTADOS E DISCUSSÃO}

O ano de 2016 foi irrefutavelmente marcado por questões políticas (leia-se política ${ }^{2}$ partidária). Desde delações, investigações, processos, prisões ao impeachment. Esse quadro marcado por intensas ações dos partidos políticos fomentou a publicação de um amplo leque de gêneros discursivos (Cartuns, Charges, Memes, Tirinhas etc.) nas redes sociais, entre os quais destacamos o Facebook. Os seis gêneros abaixo foram publicados na Página Humor Inteligente dessa rede social, ao longo do segundo semestre do ano de 2016.

Os resultados apontam que os gêneros discursivos analisados materializam distintos traços multimodais, tais como: cores, expressões faciais, formas, formatos, posições, texturas, tipografias etc. Esses traços aparecem entrelaçados à modalidade escrita da linguagem (letras, palavras e frases). Isso corrobora para a construção das informações materializadas por tais gêneros discursivos, bem como para o processo de atribuição de sentido por parte do leitor.

\footnotetext{
2 Chauí (2000) reflete acerca das distintas significações assumidas pela palavra política. Uma dessas significações diz respeito às atividades alusivas ao governo enquanto âmbito profissional. Dizendo de outra maneira, a palavra política aparece diretamente vinculada ao âmbito do governo e do estado, bem como às ações e aos sujeitos componentes desses dois âmbitos. Nesse caso, a usabilidade da palavra política aparece acompanhada do termo partidário, isto é, política partidária.
} 
Figura 1. Charge

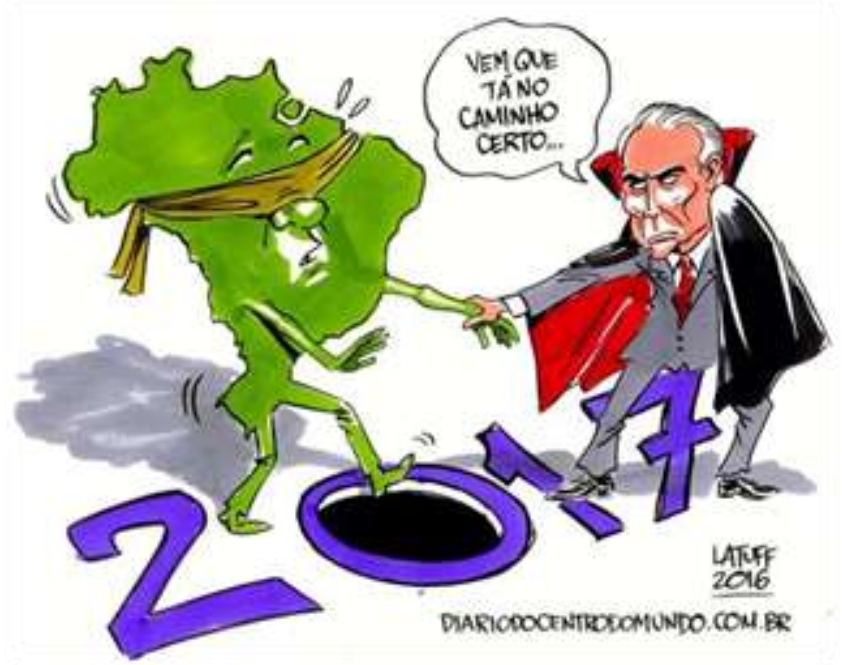

Fonte:

https://www.facebook.com/humorinteligente01/?fref=ts

A charge acima tece uma crítica à atuação de Michel Temer frente à Presidência da República. Para efetivar essa crítica, o gênero em foco mobiliza a combinação de distintos elementos, tais como: frases, imagens, cores, expressões faciais etc. De um lado, aparece a imagem do presidente da república vestido com uma capa de vampiro (típicas dos filmes de terror), estampando uma expressão facial de maldade. Do outro, aparece a imagem do mapa do Brasil com um pano nos olhos (típico das brincadeiras de cabra cega), estampando uma expressão facial de insegurança e medo. Na parte inferior, aparece o número "2017”. O número zero está preenchido pela cor preta, simbolizando um buraco negro. $\mathrm{O}$ presidente Michel Temer aparece guiando o mapa do Brasil rumo ao buraco, proferindo o seguinte enunciado "Vem que tá no caminho certo". A combinação de todos esses elementos verbais (palavras e frases) e visuais (cores, expressões faciais etc.) efetiva a materialização da crítica à atuação do atual presidente da república, evidenciando um posicionamento contrário à sua gestão. Essa combinação de diferenciadas semioses na charge em foco demonstra sua natureza multimodal.
Figura 2. Meme

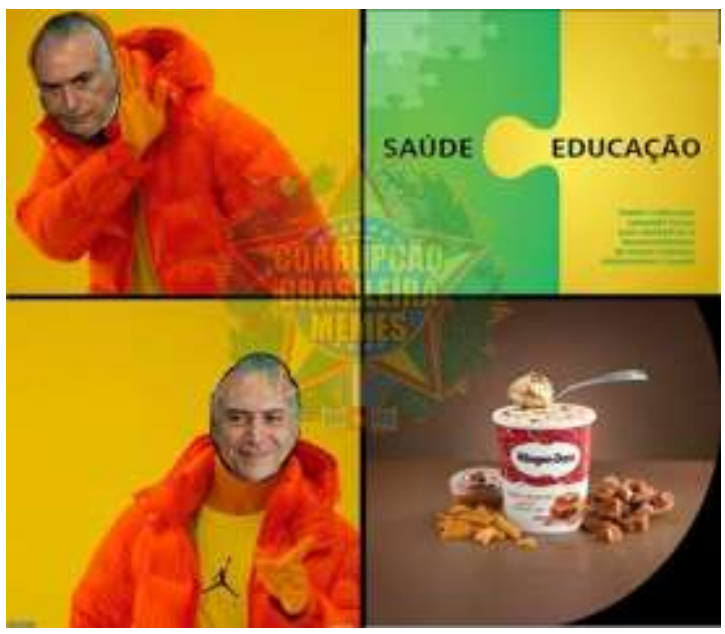

Fonte:

https://www.facebook.com/humorinteligente01/?fref=ts

O meme acima ironiza o episódio do edital de licitação para contratação de uma empresa incumbida a efetuar o abastecimento alimentício do avião presidencial. No referido edital, contavam diversos alimentos com valores bem acima do mercado, tais: creme de avelã, farinha de linhaça, geleias, sorvetes etc. $\mathrm{O}$ gênero em jogo está dividido em quatro partes (quadrados). Na parte superior, inicialmente, aparece a imagem do presidente da república, evidenciando uma expressão facial de raiva e fazendo um sinal de espera. Em seguida, aparece a imagem de um jogo de quebra-cabeças, contendo a junção entre os termos saúde e educação. Na parte inferior, de início, aparece mais uma vez a imagem do presidente da república, estampando um sorriso e apontando para frente. Em seguida, aparece a imagem de um pote de sorvete e de chocolates. Com o entrelaçamento dos elementos verbais escritos e visuais, o meme em questão não apenas ironiza o episódio supracitado, mas também postula a falta de interesse do Presidente Michel Temer por assuntos primordiais - saúde e educação - ao desenvolvimento social do Brasil. 
Figura 3. Capa de Cartilha

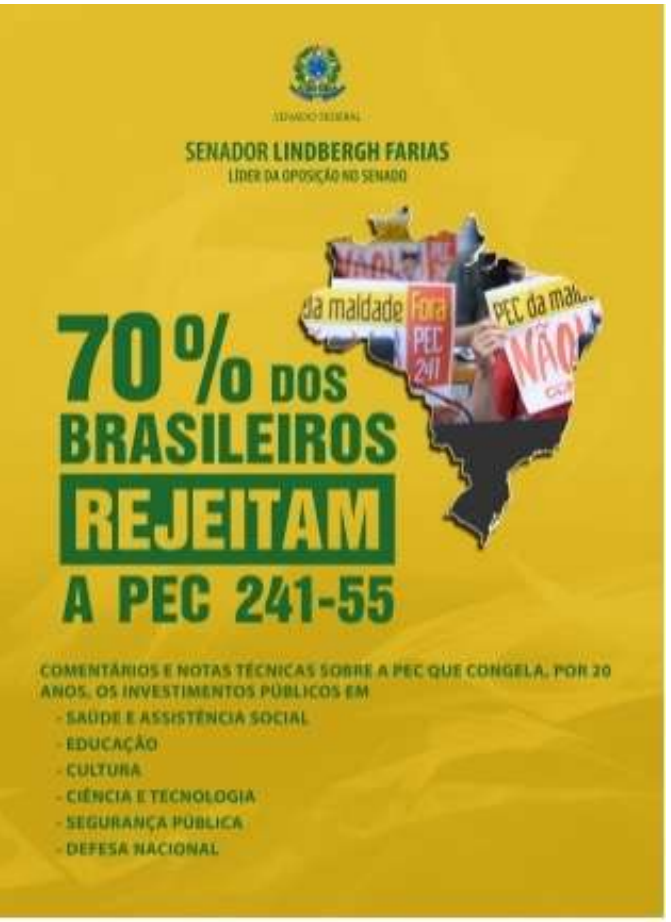

Fonte:

https://www.facebook.com/humorinteligente01/?fref=ts

A capa da cartilha contra a PEC 241-55 mobiliza distintos elementos semióticos, em prol de exteriorizar seu posicionamento contrário a essa medida. Na parte central da capa, aparece o enunciado "70\% dos brasileiros rejeitam a PEC 241 55". Nesse ponto, podemos mencionar o destaque dado à numeração $70 \%$ que possui um tamanho bem maior que os outros elementos da frase em questão. Ainda nesse enunciado, mencionamos a palavra rejeitam com um destaque marcado pela cor verde. $\mathrm{O}$ próprio enunciado em questão possui um tamanho diferenciado dos enunciados materializados na parte inferior da capa em questão. Ainda na parte central da capa, no lado direito, aparece a imagem do mapa do Brasil com o preenchimento composto por imagens de protestos contrários à PEC 241-55. O preenchimento do mapa ainda é composto pela cor preta na parte da região sul do Brasil. Na maior parte dos casos, o emprego dessa cor reflete o luto e a dor. Nesse caso, reflete a crítica. Ressaltamos, também, o preenchimento do pano de fundo da capa com a cor amarela e o uso da cor verde nos enunciados que compõem a capa. $\mathrm{O}$ emprego dessas cores remete às cores da bandeira brasileira. O entrelaçamento desses elementos semióticos - alfabéticos e imagéticos corroboram, para a efetivação da materialização do posicionamento contrário desta cartilha à PEC 24155.

Figura 4. Charge

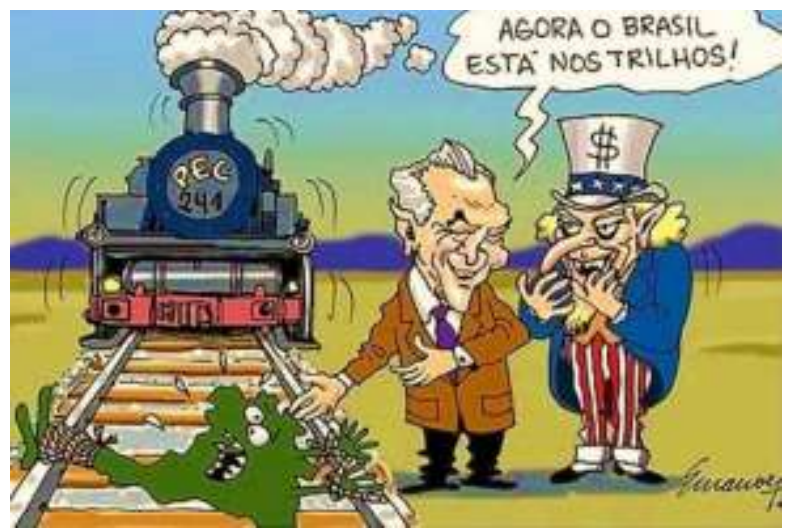

Fonte:

https://www.facebook.com/humorinteligente01/?fref=ts

A charge acima também tece uma crítica contra a PEC 241-55, mobilizando, para tal, distintos elementos, como, por exemplo, palavras, imagens/ilustrações e expressões faciais. Do lado esquerdo, aparece a imagem de um trem com a placa "PEC 241". Logo à frente, aparece a imagem do mapa do Brasil sobre os trilhos, tendo suas mãos e seus pés amarrados, exteriorizando uma expressão facial de pânico. Do lado direito, aparece a imagem do Presidente da República Michel Temer que profere o seguinte enunciado: "Agora, o Brasil está nos trilhos!". Aparece ainda a imagem do Tio San, vestindo uma roupa com a cores da bandeira americana e um chapéu com o símbolo “\$”. O que reflete o foco nos interesses financeiros. Ambos evidenciam uma expressão facial de malícia, em especial o Tio San. A partir da combinação desses distintos modos de representação (palavras, imagens e expressões faciais), a charge em tela critica a PEC 
241-55, bem como os acordos traçados em prol da obtenção de lucro monetário.

\section{Figura 5. Meme}

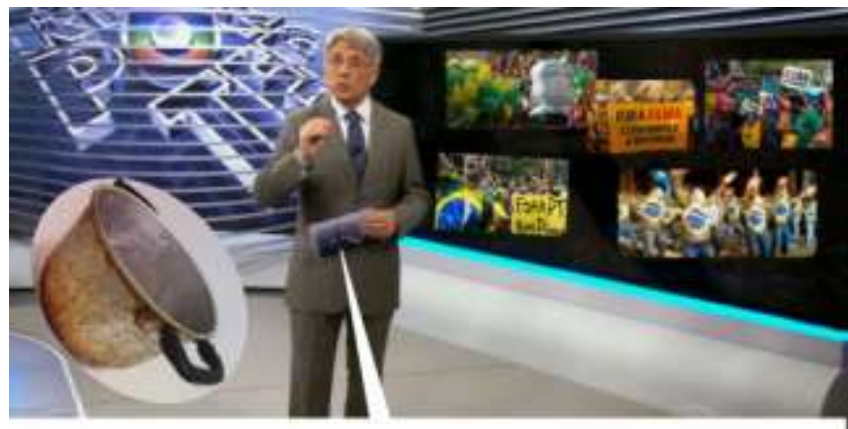

Boa noite! No programa de hoje vc vai saber o que aconteceu com os paneleiros de verde amarelo. Por onde andam? Onde enfiaram a cara? Porque se esconderam? Porque estão com vergonha? Porque não protestam mais? Tudo isso e muito mais daqui a pouco no Globo Repórter!

Fonte:

https://www.facebook.com/humorinteligente01/?fref=ts

O meme acima ironiza a extinção dos panelaços, protestos organizados por pessoas refratárias à gestão da ex-presidente Dilma Rousseff. $\mathrm{O}$ meme em foco toma como ponto de partida o cenário do Globo Repórter e a imagem do apresentador Sérgio Chapelin. O pano de fundo é dividido entre a imagem com o nome desse programa jornalístico e a imagem de uma tela com várias imagens de protestos contra o governo Dilma. Ao lado da imagem do apresentador, aparece a imagem de uma panela. Na parte inferior do meme, aparece a imagem de um texto típico da abertura desse programa jornalístico. $\mathrm{O}$ entrelaçamento dos elementos verbais escritos e imagéticos efetiva a promoção da ironia com relação à extinção dos tidos panelaços. Estes aconteciam sob pretexto de erradicar a crise econômica, bem como a corrupção do Partido Trabalhista - PT. Entretanto, as ações efetivadas pelo atual Presidente da República têm acarretado um amplo leque de insatisfações. Mesmo diante das medidas nadas animadoras promovidas pelo atual governo, os referidos panelaços deixaram de acontecer. Com a mobilização dos recursos multimodais e semióticos, o meme em questão ironiza o desaparecimento dos tidos panelaços.

Figura 6. Charge

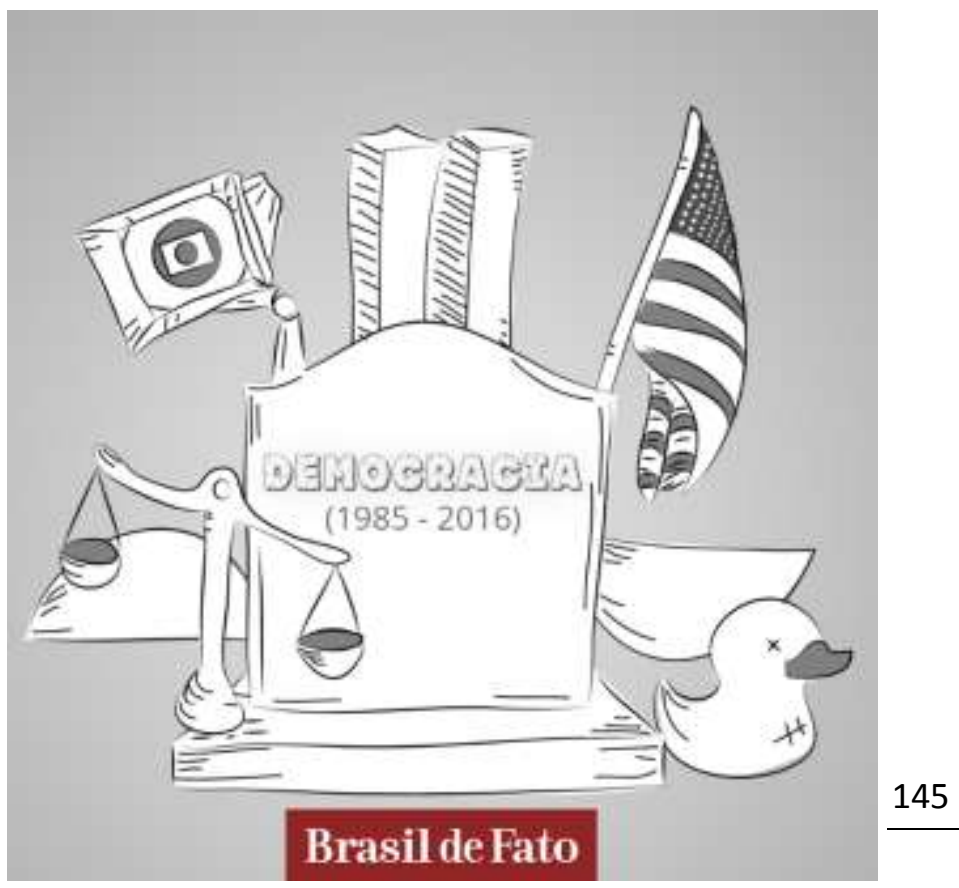

Fonte:

https://www.facebook.com/humorinteligente01/?fref=ts

A charge acima tece uma crítica ao atual quadro político brasileiro, bem como à erradicação da democracia. Para realizar essa faceta, a charge em jogo focaliza distintos aspectos que corroboraram para a efetivação do impeachment da ex-presidente Dilma Rousseff. No centro da charge, aparece a imagem de um túmulo com o seguinte enunciado “Democracia (1985-2016)". Tal imagem remete à morte e, por conseguinte, à dissipação da democracia brasileira. Por trás do túmulo, aparece a imagem do Senado Brasileiro, o que remete ao crivo político. Do lado esquerdo, na posição inferior, aparece o símbolo da justiça que, por sinal, está em uma posição de declínio. A posição inferior e a posição de declínio estão mobilizadas com o propósito de evidenciar que 
a justiça está em segundo plano ou em baixa. Do lado esquerdo, na parte superior, aparece a imagem de uma televisão, contendo a logomarca da Rede Globo.

A posição da televisão efetiva uma crítica ao posicionamento dessa rede de televisão. Do lado direito, na parte inferior, aparece a imagem de um pato, o que remete aos partidos de direita. Ainda no lado direito, na parte superior, aparece a imagem da bandeira dos Estados Unidos da América - EUA, remetendo aos interesses financeiros subjacentes ao quadro do impeachment. A mobilização de todos esses elementos alfabéticos e semióticos (as imagens, as disposições das imagens, os jogos entre a posição inferior e superior etc.) concretiza a crítica ao quadro político atual, bem como aos distintos fatores imbricados na efetivação do impeachment. O que, conseguintemente, reflete a natureza multimodal do gênero em foco.

Todos os gêneros, aqui analisados, se configuram como multimodais, visto que angariam o entrelaçamento de diferenciados modos semióticos. Esses gêneros materializam elementos verbais escritos e elementos semióticos. Dessa combinação, emergem distintos recursos discursivos, que alavancam determinados efeitos de sentido que remetem ao plano visual. Os elementos dispostos na materialidade de cada um desses gêneros (seja de cunho verbal escrito ou semiótico) foram selecionados cuidadosamente selecionados, objetivando angariar um determinado efeito. Fazem parte desse leque de elementos: o enfoque concedido a uma determinada cor, o tamanho das letras, o preenchimento do pano de fundo do gênero, o uso de determinadas expressões faciais das personagens, a escolha de determinadas imagens/ilustrações (algumas delas vinculadas a estereótipos propagados no conhecimento de mundo dos leitores), a utilização de determinadas posições dos objetos etc.
A escolha desses recursos discursivos está diretamente atrelada à mensagem a ser veiculada pelo gênero discursivo. Ou seja, em virtude da mensagem a ser deflagrada pelo gênero, o autor/enunciador seleciona distintos elementos verbais escritos $\mathrm{e}$ semióticos que subsidiam o processo de construção da informação, bem como projetam determinados efeitos de sentido.

Nessa conjectura, a escolha dos elementos escritos e semióticos que serão propalados na materialidade dos gêneros discursivos não acontece do nada. Pelo contrário, tais escolhas são procedentes de um planejamento estratégico do autor/enunciador canalizado a alavancar pistas textuais atinentes ao seu posicionamento, bem como a corroborar com a produção de sentido.

\section{CONCLUSÃO}

Diante das análises, aqui postas, é possível ressaltarmos que os gêneros discursivos em destaque materializam o entrelaçamento de elementos verbais escritos e semióticos, configurando-se, desse modo, como gêneros multimodais. Cada um dos elementos dispostos na materialidade linguística desses textos foi cuidadosamente selecionado, almejando alavancar determinados efeitos sentidos nos seus leitores. Em outras palavras, a mobilização de cada um desses elementos é planejada pelo autor/enunciador do texto, objetivando que seu leitor/coenunciador elabore sentido diante de todo esse leque de marcas expressas na materialidade linguística dos gêneros discursivos.

No entanto, o aspecto que gostaríamos de ressaltar diz respeito ao fato de, a partir dos gêneros multimodais, o processo de atribuição ou produção de sentido é algo derivado não apenas do código alfabético da escrita. Pelo contrário, o sentido é resultante da combinação de frases, cores, formas, destaques, expressões faciais, gestos, disposições de 
objetos, preenchimentos, tamanhos de fontes diferenciados etc. No lastro da roupagem da multimodalidade discursiva, a compreensão textual transcende a decodificação frasal e informacional.

É com esse olhar que postulamos a necessidade de um processo educativo canalizado a formar leitores competentes e proficientes. Estes, por sua vez, devem lidar com textos construídos mediante a concatenação de distintas modalidades linguísticas (escrita e visual). Ou seja, textos derivados da atuação de um amplo leque de semioses. Mas como viabilizar a efetivação desse processo educacional?

$\mathrm{O}$ primeiro ponto que podemos mencionar diz respeito à efetivação de trabalho pedagógico alicerçado na perspectiva da diversidade textual. Ou seja, as atividades de leitura devem envolver distintos gêneros discursivos, englobando tanto os gêneros escritos, quantos os multimodais. No entanto, não é simplesmente levar um dado gênero para a sala de aula. É necessária a realização de um trabalho em torno das suas características sociocomunicativas.

Para Santos, Mendonça \& Cavalcante (2007), o trabalho pedagógico com gêneros discursivos deve mobilizar a abordagem das suas especificidades e particularidades, a saber, intenção comunicativa, conteúdo temático, composição e estivo verbal. Diante dessa acepção, o trabalho pedagógico do(a) docente deve estimular a reflexão do alunado a respeito dessas características sociocomunicativas dos gêneros discursivos.

No que tange aos gêneros multimodais, não dever ser diferente. Dizendo de outro modo, o trabalho pedagógico do(a) docente dever abordar as especificidades e as particularidades dos gêneros multimodais, demonstrando seus arranjos visuais, bem como os efeitos de sentidos emergidos do entrelaçamento da escrita verbal e dos elementos semióticos.

Nessa conjectura, as atividades de leitura presentes nas rotinas educacionais devem envolver os distintos gêneros multimodais presentes nas distintas esferas sociocomunicativas, viabilizando o acesso do alunado aos distintos exemplares de gêneros discursivos propalados nas tramas cotidianas. É na escola que o aluno vai conhecer as características sociocomunicativas desses gêneros com fins a lidar com eles nas tramas cotidianas.

$\mathrm{Na}$ sociedade atual, são requeridas dos sujeitos distintas competências e habilidades leitoras que devem ser empregadas nas suas demandas cotidianas. Emerge, assim, a precisão de um processo educacional estribado no vasto contingente de apetrechos e artefatos semióticos propalados na esfera cotidiana. Isto é, um processo educacional alicerçado nas multiplicidades de formatos textuais (escritos, falados, imagéticos, multimodais etc.), bem como lidar com multiplicidade de linguagens e semioses difusas nas práticas corriqueiras do dia a dia, como suscita Rojo (2012).

Todos os autores declararam não haver qualquer potencial conflito de interesses referente a este artigo.

\section{REFERÊNCIAS}

ALBUQUERQUE, E. B. C.; COUTINHO, M. L.. Atividades de leitura nos livros didáticos de Língua Portuguesa. In: BARBOSA, M. L. F. F.; SOUZA, I. P.. Práticas de leitura no Ensino Fundamental. Belo Horizonte: Autêntica, 2006.

BARBOSA, M. L. F. F.; SOUZA, I. P.. Práticas na sala de aula: avançando nas concepções de Leitura. In: BARBOSA, M. L. F. F.; SOUZA, I. P. (Org.). Práticas de leitura no Ensino Fundamental. Belo Horizonte: Autêntica, 2006.

BEAUGRANDE, R. A., DRESSLER, W. U.. Introduction to Text Linguistics. London: Longman, 1981.

BEZERRA, M. A. Ensino de língua portuguesa e contextos teórico-metodológicos. In: DIONÍSIO, A. P.; MACHADO, A. R.; BEZERRA, M. A.. (Org.). 
Gêneros textuais \& ensino. São Paulo: Parábola Editorial, 2010.

Textos: seleção variada e atual. In: DIONÍSIO, A. P.; MACHADO, A. R.. (Org.). O livro didático de português: múltiplos olhares. Rio de Janeiro: Lucerna, 2001.

BOMFANTE, Z.. A concepção de texto e discurso para semiótica social e o desdobramento de uma leitura multimodal. Revista Gatilho (PPGL/ UFJF), v. $13, \quad$ p. 8, 2011. Disponível em: http://www.ufjf.br/revistagatilho/files/2011/10/Santos .pdf. Acesso em: 17 set. 2016.

BRASIL. Secretaria de Educação Fundamental. Parâmetros Curriculares Nacionais: Língua Portuguesa. Secretaria de Educação Fundamental. Brasília, $1998 . \quad$ Disponível em: http://portal.mec.gov.br/seb/arquivos/pdf/livro02.pdf. Acesso em: 07 nov. 2016.

Secretaria de Educação Fundamental. Parâmetros Curriculares Nacionais: Língua Portuguesa. Secretaria de Educação Fundamental. Brasília, $1997 . \quad$ Disponível em: http://portal.mec.gov.br/seb/arquivos/pdf/livro01.pdf. Acesso em: 07 nov. 2016.

CHAUÍ, M.. Convite à Filosofia. São Paulo: Ática, 2000.

DIONISIO, A. P.. Gêneros textuais e multimodalidade. In: KARWOSKI, A. M.; GAYDECZKA, B.; BRITO, K. S. (Orgs.). Gêneros Textuais: reflexões e ensino. São Paulo: Parábola, 2011.

FUZA, A. F.; OHUSCHI, M. C. G.; MENEGASSI, R. J.. Concepções de linguagem e o ensino da leitura em língua materna. Linguagem \& Ensino, v. 14, n. 2, p. 479-501, 2012. Disponível em: http://www.rle.ucpel.tche.br/index.php/rle/article/vie w/36. Acesso em: 07 set. 2016.

KLEIMAN, B.. Texto e Leitor: aspectos cognitivos da leitura. Campinas: Pontes, 1989.

KOCH, I. G. V.; ELIAS, V. M.. Ler e compreender: os sentidos do texto. São Paulo: Contexto, 2006.

LUNA, T. S.; MARCUSCHI, B.. Letramentos Literários: o que se avalia no Exame Nacional do Ensino Médio?. Educação em Revista, v. 31, n. 3, $2015 . \quad$ Disponível em: http://www.scielo.br/pdf/edur/2015nahead/01024698-edur-135569.pdf. Acesso em: 01 jan. 2017.
ROJO, R. Pedagogia dos Multiletramentos: diversidade cultural e de imagens na escola. In: ROJO, R.; MOURA, E. (Orgs.). Multiletramentos na Escola. São Paulo: Parábola Editorial, 2012.p. 11-32.

SANTOS, C. F.. Formação em Serviço do Professor e as Mudanças no Ensino de Língua Portuguesa. Educação Temática Digital - ETD, Campinas, SP, vol.3, $\mathrm{n}^{\circ}$. 2, p.27-37, jun. 2002a. Disponível em: http://www.fae.unicamp.br/revista/index.php/etd/artic le/view/1794. Acesso em: 16 jul. 2016.

O ensino da leitura e a formação em serviço do professor. Teias, Rio de Janeiro, ano 3, v. 05, n. jan/jun, p. 29-34, 2002b. Disponível em: http://www.periodicos.proped.pro.br/index.php/revist ateias/article/view/95. Acesso em: 20 jul. 2016.

SANTOS, C. F.; MENDONÇA, M.; CAVALCANTI, M. C. B.. Trabalhar com texto é trabalhar com gênero?. In: SANTOS, C. F.; MENDONÇA, M.; CAVALCANTI, M. C. B. (Orgs.). Diversidade Textual: os gêneros na sala de aula. Belo Horizonte: Autêntica, 2007.

SILVA, A.; MORAIS, A. G.. Entre Tradição e Inovação: um estudo sobre mudanças no ensino de gramática em livros didáticos brasileiros de Língua Portuguesa. Revista Portuguesa de Educação, v. 24, p. 119-144, 2011. Disponível em: http://www.scielo.mec.pt/pdf/rpe/v24n1/v24n1a06.pd f. Acesso em: 04 jun. 2016.

SILVA, S. P.. O Texto Visual na Educação Infantil: Contribuições para Construção do Conhecimento da Criança. Arredia, Dourados, v. n. ${ }^{\circ}$ 03, p. 77-101, 2014a. Disponível em: http://www.periodicos.ufgd.edu.br/index.php/arredia/ article/view/3290/2058. Acesso em: 22 set. 2016.

Pedagogia da leitura: quais as teorias subjacentes?. Travessias, v. n. ${ }^{\circ}$ 08, p. 288-299, 2014.Disponível em: http://erevista.unioeste.br/index.php/travessias/article/view/1 0888. Acesso em: 01 jan. 2017.

SILVA, S.P.; SOUZA, F. E. B.; SILVA, S.P.; CIPRIANO, L. C. (2015). Textos Multimodais: um Novo Formato de Leitura. Linguagem em (Re)vista, vol. 10, n. 19. Niterói, jan.-jun.. Disponível em: http://www.filologia.org.br/linguagememrevista/19/0 8.pdf. Acesso em: 25 set. 2016.

SILVA, S. P.; LUNA, T. S.. Da decodificação à construção de sentido: concepções de leitura subjacentes aos livros didáticos de língua portuguesa e adotados pela secretaria de educação do estado de 
Pernambuco (1979-2012). Olh@ res, v. 1, n. 2, p. 365-388, 2013.

Disponível

em:

http://www.olhares.unifesp.br/index.php/olhares/artic le/view/67. Acesso em: 06 set. 2016.
SOARES, M. B.. Novas Práticas de Leitura e Escrita: letramento na cibercultura. Educação e Sociedade, v. 23, n. 81, p. 143-160, 2002. Disponível em: http://www.scielo.br/pdf/es/v23n81/13935.pdf.

Acesso em: 20 jan. 2017. 